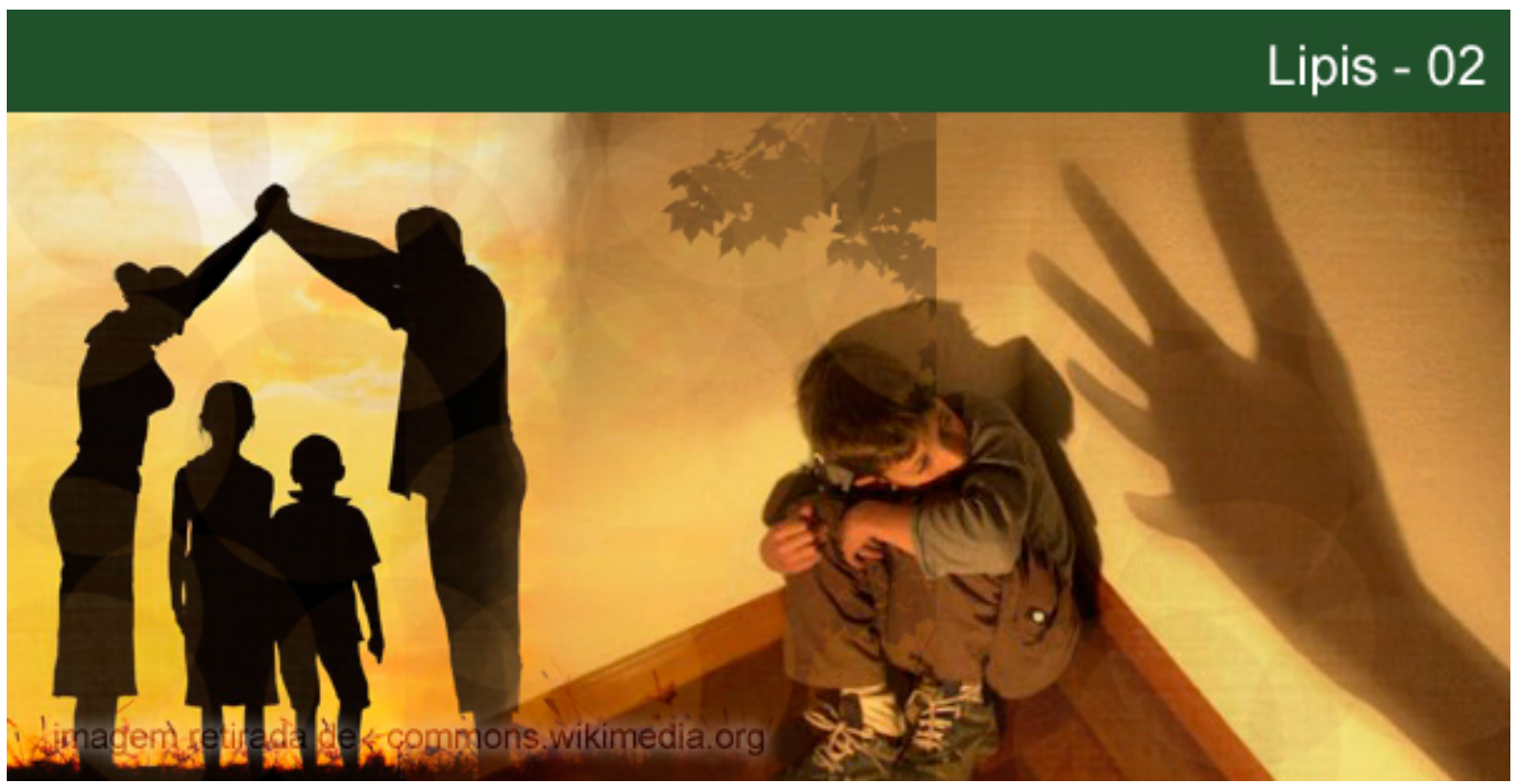

\title{
É POSSÍVEL PROFISSIONALIZAR AS FAMÍLIAS ACOLHEDORAS NO BRASIL?
}

\section{Rachel Baptista}

Doutoranda em Psicologia clínica pela Pontifícia Universidade Católica (PUC-Rio). Bolsista CAPES-Prosup. Possui Mestrado em Serviço Social - PUC-Rio-2006. Atuou como Conselheira na X Plenária do Conselho Regional de Psicologia (CRP/05). Tem experiência nas áreas de docência, pesquisa e clínica tendo como principais interesses os temas relacionados à infância, violência e direitos humanos. Atualmente é professora assistente I da Universidade Estácio de Sá (UNESA) - Departamento de Serviço Social. Pesquisador Associado do Laboratório Interdisciplinar de Pesquisa e Intervenção Social - LIPIS, da PUC-Rio. É sócia da Associação Brasileira de Psicologia Social (ABRAPSO-RJ). E-mail: rachelbta@gmail.com.

\section{Maria Helena Zamora}

Professora da Pós-graduação em Psicologia Clínica na PUC-Rio. Vice-coordenadora do Laboratório Interdisciplinar de Pesquisa e Intervenção Social - LIPIS/PUC-Rio.E-mail: zamoramh@gmail.com.

Resumo: A família acolhedora, alternativa de proteção para lidar com casos de violência doméstica e violação de direitos contra crianças e adolescentes, é prioridade no atendimento, nos casos definidos, segundo previsão legal brasileira. Famílias acolhedoras tornam-se guardiães legais durante um prazo determinado, ficando responsáveis por prestar assistência e cuidados, de forma ampla. Este estudo tem por objetivo questionar o caráter de trabalho voluntário das mesmas no Brasil. Para isso, são trazidos os aspectos legais que dão subsídios a essa prática, bem como um breve recorte sobre as práticas de acolhimento em outros países. Entende-se que a profissionalização dos acolhedores pode ser uma forma de viabilizar o processo de implementação desta importante política pública.

Palavras-chave: Família acolhedora. Direitos da criança. Política pública. Violência na família.

\section{CAN FOSTER FAMILIES BE A PROFESSION IN BRAZIL?}

Abstract: The foster family, protective alternative for dealing with cases of domestic violence and violation of rights against children and adolescents, is, according to Brazilian legal provision, priority attention in the cases defined. Foster families become legal guardians for a specified period, and were responsible for providing assistance and care, broadly. This study aims to question the character of volunteer foster families in Brasil. To do so, the legal aspects are brought to give subsidies to this practice, as well as a short cut on the host practices of the foster care in other countries. It is understood that the professionalization of the reception, can be a way of facilitating the implementation process of this important public policy.

\section{POLÊM!CA $\mid$ LABORE}

Polêmica - Revista Eletrônica da Uerj - Rua São Francisco Xavier, 524, $1^{\circ}$ andar bloco D, sl.1001 • Tels.: +55 21 2334-4088 / 4087 • http://www.e-publicacoes.uerj.br/index.php/polemica/index http://www.labore.uerj.br • laboreuerj@yahoo.com.br 
Keywords: Foster care. Children’s rights. Public policy. Family violence.

\section{Introdução}

O acolhimento familiar é uma prática antiga de cuidados e utilizada por diferentes sociedades, com características culturais peculiares. De modo amplo, esta forma de lidar com situações de vulnerabilidade é conhecida em diferentes países e, segundo Dantas \& Luna (2009), caracteriza-se como uma possibilidade de convívio familiar para crianças cujas famílias de origem não estão em condições de assumí-las. Não há vinculação filiatória por parte de quem acolhe e o respeito à identidade e cultura de cada uma deve ser preservado.

No caso específico deste artigo tratamos do acolhimento de crianças ${ }^{1}$ e adolescentes que precisam de proteção. Respaldados no Estatuto da Criança e do Adolescente (ESTATUTO-ECA, BRASIL, 1990) e após sua revisão em 2009 (Lei da Adoção), a família acolhedora no Brasil é aquela que se propõe a ocupar, provisoriamente, o lugar de cuidadora e protetora respeitando as particularidades de cada um. Aqui esta é uma prática voluntária e as famílias que acolhem não recebem rendimentos direcionados ao seu trabalho. Nem sequer são vistas como profissionais de acolhimento.

Diante da circulação das crianças (FONSECA, 2006) por diferentes espaços em busca de cuidados e proteção, da necessidade de manter e resgatar os vínculos afetivos e de pertencimento e da urgência em ampliar as formas de acolhimento para além das instituições, foi pensada uma alternativa que pudesse ter como base o modelo de família como núcleo solidário de apoio e disponibilidade afetiva. Advindas de instituições de acolhimento, das ruas, de locais com estrutura física pouco adequada ao seu desenvolvimento, de relações descontínuas com seus cuidadores ou outras situações que as coloca em vulnerabilidade, algumas crianças têm sido encaminhadas às famílias acolhedoras.

Enfatizamos também o acolhimento como iniciativa importante para lidar com a violência doméstica. Muitas condutas violentas, mesmo não intencionais, violam os direitos humanos de crianças (GUERRA, 2011) e precisam ser olhadas. A prática profissional retrata um número considerável do encaminhamento das mesmas aos serviços protetivos por motivo de negligência ou pelo que assim é compreendido (MIRANDA \& ZAMORA, 2009). Esta

\footnotetext{
${ }^{1}$ O termo criança está contemplado na Convenção Internacional sobre os Direitos da Criança e diz respeito a crianças e adolescentes com até 18 anos incompletos. No texto será utilizado o mesmo termo.
}

\section{POLÊM!CA | LABORE:}


forma de reduzir o outro a um lugar de objeto, coisificando-o, é também um abuso de poder que vitimiza a infância e nega seus valores humanos fundamentais.

Em outros casos, a própria família de origem pede ajuda aos atores principais e/ou secundários envolvidos no acolhimento por conta de uma situação extrema de vulnerabilidade. Destaca-se, especificamente, a condição de pobreza e pouca ou nenhuma rede de apoio como sendo os motivadores do pedido de separação. Note-se que na legislação atual, o Estatuto não mais prevê a destituição ou suspensão do poder familiar por motivo de pobreza (Art. 23). No entanto, este ainda é um motivo frequente para intervenção judicial.

No Brasil, a experiência formal de acolhimento em famílias é bastante recente (década de 1940) e surgiu com o intuito de se pensar em alternativas à institucionalização, já que os malefícios desta prática tornaram-se explícitos. Somente depois da criação e revisão do Estatuto, em 2009, foi garantida essa alternativa de forma prioritária, enfatizando-se a importância de sua aplicação antes de se pensar no encaminhamento institucional.

Junto a esta reformulação teve grande importância a discussão das novas formas de configurações familiares (VILHENA et al., 2011) já que a visão da antiga família nuclear burguesa vem sendo desconstruída ao longo dos anos e as famílias que acolhem acompanham esta mudança. Tal aprofundamento teórico propiciou o repensar das diferentes formas de vínculos e arranjos familiares, para além do modelo patriarcal como ideal e único para a criação dos filhos.

Neste artigo tratamos dos casos onde a intervenção da justiça se faz necessária para a regularização do afastamento da criança de sua família de origem ${ }^{2}$. A mesma é encaminhada a outra família já constituída e devidamente selecionada e treinada para o acolhimento. Contudo, a primeira opção antes da separação é a busca por alguém da chamada família extensa (avós, tios, primos, irmãos adultos, parentes próximos) que possa se responsabilizar pelo cuidado.

Quando não é possível a continuidade do cuidado por um familiar próximo ou alguém com vínculo significativo, o serviço de família acolhedora é acionado. Também chamada de “família de apoio”, “família guardiã”, “família hospedeira” - ela fica responsável por cuidar, orientar, suprir necessidades básicas, dar afeto e propiciar o desenvolvimento integral,

\footnotetext{
${ }^{2}$ Família na qual a criança encontrava-se no momento em que sofreu intervenção judicial: biológica ou não.

\section{POLÊM!CA | LABORE:}


tornando-se guardiã legal. Compromete-se a respeitar e contribuir para a provisoriedade da medida, que objetiva a breve reintegração familiar.

O presente artigo tem como foco a problematização do caráter voluntário do acolhimento adotado no Brasil. As famílias acolhedoras aqui, em sua maioria, são constituídas por pessoas com pouca renda que, por diferentes motivações, disponibilizam-se a colaborar cuidadosamente para a restituição afetiva e social de crianças em situação de vulnerabilidade social. Essas famílias não recebem subsídios financeiros para tal atividade e devem passar por um processo de gestão de pessoas nos moldes similares aos empresariais. Contudo, não são reconhecidas como profissionais de acolhimento tal qual países como Portugal, França e Espanha. Para problematizar o caráter voluntário desta prática mencionamos certos aspectos legais e fazemos uma breve revisão crítica de literatura a respeito desta temática.

\section{Aspectos históricos e legais do Acolhimento Familiar no Brasil}

Assim como na França e em outros países, o abandono de crianças nas Rodas dos Expostos foi uma realidade brasileira (VENÂNCIO, 1999). Muitos bebês colocados neste dispositivo cilíndrico usado para deixá-los aos cuidados de instituições de caridade dali foram encaminhados para mulheres criadeiras de etnias e culturas diversas (BRASIL, 2004, P. 107). Estas, em troca de precária remuneração dispunham-se a acolher esses enjeitados e levá-los para seu ambiente de vida durante um período de tempo. O Estado raramente subsidiava essas práticas e o custeio ficava, em sua maioria, por conta das instituições católicas, as Santas Casas de Misericórdia.

Por volta dos três anos de idade as crianças sobreviventes voltavam para as casas de caridade em um movimento de reinstitucionalização, onde acabavam de ser criadas. Cabe lembrar que essas instituições tinham um regime claustral, comportavam divisões por sexo, etnia e origem de seus internos e tinham pouca ou nenhuma convivência comunitária (MARCÍLIO, 1993 \& RIZZINI, 1993). Não subsistem relatos de qualquer tipo de supervisão ou fiscalização. Provavelmente essa precariedade foi a causa de tantas mortes e maus tratos de crianças nos estabelecimentos da Roda - o que ensejou a crítica dos higienistas (RIZZINI, 1997).

O Código de Menores (Código), de 1927, foi o primeiro documento dirigido aos meninos (as) menores de dezoito anos no Brasil. Com ele o juiz tinha autoridade e ingerência centrais sobre as decisões relativas aos mesmos, sendo estes objetos de direitos. A colocação

\section{POLÊM!CA $\mid$ LABORE}

Polêmica - Revista Eletrônica da Uerj - Rua São Francisco Xavier, 524, $1^{\circ}$ andar

bloco D, sl.1001 • Tels.: +55 21 2334-4088 / 4087 • http://www.e-publicacoes.uerj.br/index.php/polemica/index http://www.labore.uerj.br • laboreuerj@yahoo.com.br 
em famílias substitutas foi prevista e formalizada passando a ser considerada uma medida que intencionava garantir-lhes um desenvolvimento mais saudável. No entanto, não havia previsão de qualquer preparo para as famílias candidatas.

Em meados do século XX, findas duas grandes guerras mundiais, as nações sobreviventes enfatizaram a preocupação com a infância no mundo destroçado. A Organização das Nações Unidas (ONU), criada em 1945, surgiu com a preocupação de manter a paz e a cooperação entre os países. Seguidamente, outras iniciativas eclodiram tais como a criação do United Nations Children's Fund (UNICEF), em 1946, a aprovação da Declaração Universal dos Direitos Humanos, em 1948 (PIOVESAN \& FACHIN, 2015), e a Declaração Universal dos Direitos da Criança, em 1959.

Contudo, a mudança de paradigma legal é de 1989, com a Convenção Internacional sobre os Direitos da Criança (Convenção), que estabeleceu importantes passos para a garantia da proteção integral. Em 1990, no Brasil, o Estatuto foi proposto de acordo com os princípios da Convenção e estabeleceu ser da família, da comunidade, da sociedade em geral e do Poder Público assegurar, com absoluta prioridade”, uma série de direitos, dentre eles, “o direito à vida, à liberdade e à convivência familiar e comunitária” (Art. $4^{\circ}$ ). O Estatuto reforçou a responsabilidade de todos no trato com a infância e adolescência, sem qualquer tipo de discriminação. Empoderou e responsabilizou todos os cidadãos, prevendo novas formas de participação democrática. Aliado a isso, foi criado o Conselho Nacional dos Direitos da Criança e do Adolescente (CONANDA), em 1991, que, dentre outras atribuições, deve elaborar as normas gerais da política nacional de atendimento aos direitos dessa população (BRASIL, 1991, Art. $2^{\circ}$ ).

No Brasil, houve algumas experiências de acolhimento familiar interrompidas em São Paulo (BRASIL, 1949) e no Rio de janeiro (CMDCA, 2003). Mais a frente, em 2006, representantes das instâncias governamentais e sociedade civil elaboraram o Plano Nacional de Promoção, Proteção e Defesa do Direito de Crianças e Adolescentes à Convivência Familiar e Comunitária (BRASIL, 2006). Este documento contribuiu para a formulação da Lei da Adoção (BRASIL, 2009a), que revisou o Estatuto incluindo o acolhimento como medida de proteção (ART. 101) a ser pensada com prioridade antes do encaminhamento à instituição ou adoção. Este movimento significou dar a devida importância a não institucionalização de crianças sem que antes se esgote toda e qualquer possibilidade de

\section{POLÊM!CA | LABORE}


manutenção de vínculos importantes e garantia da convivência familiar e comunitária junto ao ambiente de pertencimento da criança.

A equipe técnica responsável pelo acolhimento deve implementar ações que visem melhorar as relações nas famílias de origem, propiciando o breve retorno do acolhido: “O serviço é particularmente adequado ao atendimento de crianças e adolescentes cuja avaliação da equipe técnica indique possibilidade de retorno à família de origem [nuclear ou extensa]” (BRASIL, 2013, p. 50). Cabe ressaltar que o acolhimento familiar, a princípio, tinha como meta um público-alvo específico, ou seja, aquele cuja possibilidade de reintegração familiar fosse mais viável. No entanto, a prática tem nos mostrado que esta adequação nem sempre é possível já que há muitos casos de crianças acolhidas sem perspectivas de retorno ao ambiente inicial.

A família acolhedora é, portanto, uma política pública nacional, contemplada como uma proposta que obrigatoriamente deve ser implementada, já que está situada no nível máximo de proteção a que um sujeito de direito deve ser submetido no Brasil, a Proteção Social Especial de Alta Complexidade. É uma política direcionada à proteção integral, ou seja, "para famílias e indivíduos que se encontram sem referência e, ou, em situação de ameaça, necessitando ser retirados de seu núcleo familiar e, ou, comunitário” (BRASIL, 2004, p. 39).

No âmbito desta política ainda pouco efetivada levantamos, especificamente, a discussão a respeito de um dos possíveis entraves para sua concretização: o caráter voluntário do trabalho das famílias acolhedoras no Brasil. Para aprofundamento do tema e estabelecimento de algumas comparações pertinentes, serão examinadas, brevemente, algumas iniciativas de acolhimento em outros países.

\section{Acolhimento e profissionalização}

Não se sabe, ao certo, o que estimula uma família ao acolhimento. A escuta, ao longo da experiência pessoal, mostra que o sentimento de solidariedade parece estar realmente presente na grande maioria dos casos. Quando se pergunta aos cuidadores o que pode melhorar no exercício do acolhimento, o discurso sobre as dificuldades financeiras na criação dessas crianças aparece constantemente, a longo tempo; mesmo em outros países:

Ganhar dinheiro com acolhimento pode parecer repugnante para aqueles que veem essa alternativa como uma contribuição... Perder dinheiro, junto com outros

\section{POLÊM!CA | LABORE}

Polêmica - Revista Eletrônica da Uerj - Rua São Francisco Xavier, 524, $1^{\circ}$ andar bloco D, sl.1001 • Tels.: +55 21 2334-4088 / 4087 • http://www.e-publicacoes.uerj.br/index.php/polemica/index http://www.labore.uerj.br • laboreuerj@yahoo.com.br 
sacrifícios e custos de assistência social não é justo, especialmente quando o dinheiro pode ser investido em uma melhor qualidade de vida para toda a família, incluindo as crianças acolhidas ${ }^{3}$ (GEORGE \& VAN OUDENHOVEN, 2003, p. 95).

O fato das profissões ligadas à proteção dos direitos das crianças e adolescentes terem remuneração parece romper com uma certa idealização romântica para alguns autores atrelados à herança caritativa da época menorista, como mostram alguns estudos sobre os conselhos tutelares (AZEVEDO, 2007 \& CANTALICE, 2011). Até hoje, muitos conselheiros se defrontam com o desafio de viver com salários muito baixos ou sem qualquer remuneração. Entende-se que tal lógica pode reproduzir-se ao associar o trabalho com crianças com uma escolha amorosa e incompatível com remuneração salarial e direitos trabalhistas.

Mudar a lógica de atendimento no trato com a infância é uma das prioridades trazidas pelas Orientações Técnicas: serviços de acolhimento para crianças e adolescentes (BRASIL, 2009b) a respeito dos serviços de acolhimento no Brasil. No entanto, essas diretrizes não tratam da profissionalização do acolhimento de maneira específica, pois desconsideram os pais acolhedores como trabalhadores sociais. Contudo, há mais de uma década, já se pensava na importância da profissionalização desses cuidadores em outros países, onde as qualidades profissionais parecem ser igualmente necessárias àquelas relacionadas ao sentimento de solidariedade que as tem feito acolher: “A tendência a sua maior profissionalização parece irreversível, bem como a necessidade de pagá-los por seus serviços, [há] baixa consciência de que o altruísmo e a remuneração não são incompatíveis” ${ }^{4}$ (GEORGE \& VAN OUDENHOVEN, 2003, p. 78).

Questionamos a viabilidade político-financeira de se fazer um trabalho exclusivamente voluntário nesse contexto onde é exigido, de acordo com as Orientações Técnicas, todo um aparato de habilidades e aptidões, respaldado também na psicologia organizacional, que, em geral, trata dos processos de recrutamento, seleção e treinamento: “um processo de seleção e treinamento criterioso é essencial para a obtenção de famílias acolhedoras com perfil adequado ao desenvolvimento de suas funções, possibilitando a oferta de um serviço de qualidade aos usuários” (BRASIL, 2009c, p. 49).

\footnotetext{
${ }^{3}$ Texto original: Hacer dinero del acogimiento puede resultarle repugnante a aqueéllos que ven a esta alternativa como una contribución... Perder dinero, junto con otros sacrificios y costos que implica el acogimiento, no es justo, especialmente cuando el dinero puede invertirse en una mejor calidad de vida para todos los de la familia, incluyendo a los ninõs acogidos.

${ }^{4}$ Texto original: La tendencia a su mayor profesionalización parece irreversible, así como también la necesidad de pagarles por sus servicios, bajo conciencia de que el altruismo y la remuneración no son incompatibles.
}

\section{POLÊM!CA | LABORE:}

Polêmica - Revista Eletrônica da Uerj - Rua São Francisco Xavier, 524, $1^{\circ}$ andar bloco D, sl.1001 • Tels.: +55 21 2334-4088 / 4087 • http://www.e-publicacoes.uerj.br/index.php/polemica/index http://www.labore.uerj.br • laboreuerj@yahoo.com.br 
A precariedade na capacitação dos cuidadores e técnicos envolvidos no processo de acolhimento familiar pode ser constatada como uma fragilidade desse serviço (COSTA \& ROSSETI-FERREIRA, 2009; VALENTE, 2013; BAPTISTA, 2014). A qualificação continuada dos mesmos vem se constituindo, há algum tempo, como um elemento fundamental nessa prática intervencionista. Da mesma forma, as estratégias de captação das famílias e monitoramento dos serviços (LÓPEZ, DEL VALLE \& ARTEAGA, 2010). A valorização profissional daqueles que compõem a rede de proteção das crianças e adolescentes com direitos violados (BAPTISTA, 2006) é necessária diante de um novo perfil profissional desejado:

Características pessoais desejáveis: motivação para a função, aptidão para o cuidado com crianças e adolescentes; capacidade de lidar com frustração e separação; habilidade para trabalhar em grupo; disponibilidade afetiva; empatia; capacidade de mediação de conflitos; criatividade; flexibilidade; tolerância; pro-atividade; capacidade de escuta; estabilidade emocional (...) (BRASIL, 2009b, P. 25).

Assim como em outros países, as famílias mais abastadas não são as mais interessadas no acolhimento familiar formal. Aquelas que acolhem, em sua maioria, estão em classes populares e precisam de suporte financeiro para dar conta das necessidades materiais dos meninos (as). Além disso, o investimento no desenvolvimento de competências específicas requer treinamento por profissionais capacitados, o que gera nova despesa. Nesse contexto, pensar no salário como um reconhecimento do trabalho executado parece ser importante.

Delgado (2010) corrobora a importância de levar em conta o aspecto humanitário do acolhimento, no entanto esclarece que os saberes profissionais são tão importantes para este tipo de trabalho quanto o sentimento solidário das famílias. Segundo ele, uma das desvantagens de não se profissionalizar os acolhedores é a pouca preparação que os mesmos acabam tendo para lidar com questões muito complexas relacionadas às histórias de vida das crianças. O autor reforça a importância de um processo de gestão amplo e com a devida avaliação continuada para que se possa adequar novas formações preparatórias das famílias.

Outros profissionais da rede de atenção, atuantes no contexto social, são remunerados. O desejo de fazer parte deste cenário pode estar relacionado ao fato de gostar e querer acolher, aliado à necessidade financeira de subsistência. Isso é real no contexto laboral e não diminui o comprometimento com o trabalho. É apenas um dos estímulos para o acolhimento e pode não ser o principal (GIRARD, 2004).

\section{POLÊM!CA $\mid$ LABORE}

Polêmica - Revista Eletrônica da Uerj - Rua São Francisco Xavier, 524, $1^{\circ}$ andar bloco D, sl.1001 • Tels.: +55 21 2334-4088 / 4087 • http://www.e-publicacoes.uerj.br/index.php/polemica/index http://www.labore.uerj.br • laboreuerj@yahoo.com.br 
Para alguns estudiosos, o cunho profissional pode facilitar o processo provisório de transferência de guarda. Delgado (2010) cita o exemplo da perspectiva do acolhimento profissional como sendo compatível entre o profissionalismo e a vida familiar na qual os acolhedores atuam como pais, sem que estes pretendam ocupar o lugar da família de origem. Estariam assim estabelecendo um distanciamento necessário para essa prática, onde a intenção não é a adoção.

O trabalho social, como qualquer outro, não se desvincula da discussão a respeito de custos e a remuneração de quem cuida precisa ser levada em consideração. Questionamos a escassez de recursos financeiros direcionados para a Assistência Social no Brasil. No entanto, a desvalorização dos profissionais sociais não acontece somente aqui, esta prática é observada também em países centrais, submetidos às investidas neoliberais que resultaram na redução do estado social (JOYCE \& SKIBIETA, 2013). Contudo, a infância, segundo princípio constitucional brasileiro, deve ter prioridade absoluta na construção e implementação de políticas públicas.

Valente (2012), baseada na Política Nacional de Assistência Social, enfatiza que é nítida a necessidade de maior investimento na Proteção Social Especial de Alta Complexidade, ou seja, naqueles casos onde há necessidade urgente de proteção. O gestor desta política é o Estado, que nas ações intersetoriais deve garantir, com absoluta prioridade, a vida de crianças em família e na comunidade, preferencialmente em sua família de origem.

\section{Discussão}

Os serviços ou programas de famílias acolhedoras no Brasil são de caráter voluntário (BRASIL, 2009a). Segundo as Orientações Técnicas (BRASIL, 2009b), quando é preciso direcionar algum subsídio financeiro para os acolhedores, este não deve se caracterizar uma atividade remunerada em nível trabalhista. O valor destinado pelas prefeituras aos acolhimentos varia e nem todos os gestores entregam o dinheiro diretamente às famílias. Em alguns casos as necessidades são geridas pelos técnicos que procuram atender às demandas na medida do possível. Não há remuneração pelo trabalho, mas uma ajuda de custo para o sustento das crianças acolhidas e grande incentivo ao voluntariado mesmo diante da realidade brasileira de desigualdade social, permeada pela pobreza e miséria.

Este fato gera muitos desafios diante da prática diária de trabalho com famílias acolhedoras. Para discutir esse viés, partimos de três pressupostos: 1) o acolhimento em

\section{POLÊM!CA $\mid$ LABORE}

Polêmica - Revista Eletrônica da Uerj - Rua São Francisco Xavier, 524, $1^{\circ}$ andar bloco D, sl.1001 • Tels.: +55 21 2334-4088 / 4087 • http://www.e-publicacoes.uerj.br/index.php/polemica/index http://www.labore.uerj.br • laboreuerj@yahoo.com.br 
famílias acolhedoras é prioridade absoluta antes de qualquer tentativa de institucionalização (BRASIL, 2009a) logo, deve ser garantido por meio de políticas públicas; 2) diversos pensadores da infância constataram a importância dos cuidados em ambiente estável e seguro para o desenvolvimento da saúde mental, portanto a família acolhedora estaria ocupando, provisoriamente, este lugar; 3) as políticas que garantem sua efetivação precisam subsidiar as famílias dispostas a acolher.

O acolhimento familiar no Brasil está acontecendo aquém do que deveria. Desigualdade social, pobreza e negligência (LUNA, 2010; ASSIS \& FARIAS, 2013) parecem ser motivadores da circulação de crianças que são alvo do acolhimento. Neste contexto, as famílias menos favorecidas financeiramente também são as mais presentes na proposta de acolher. Em recente investigação, Baptista (2014) encontrou resultados que corroboram a importância do acolhimento em famílias acolhedoras como alternativa de cuidados reconhecidamente benéfica em substituição à institucionalização. No entanto, foi observada a presença de enormes desafios na prática diária.

A partir da indagação a respeito das dificuldades dos profissionais de acolhimento na implementação e manutenção desta política foi destacada a quantidade insuficiente de famílias dispostas a acolher. Este fato pode estar diretamente ligado à dificuldade financeira da população que deseja contribuir com o serviço. Está dado um problema a ser enfrentado. Soma-se a esses dados a cultura de institucionalização ainda muito presente na mentalidade brasileira (DIAS \& SILVA, 2012) e a necessidade de repensá-la (COSTA \& ROSSETTIFERREIRA, 2009).

Esta medida protetiva é reconhecida como alternativa importante, tem prioridade legal e sua efetivação para a promoção dos direitos se faz necessária já que a intenção é proporcionar cuidados estáveis. No entanto, nem sempre vem sendo garantida. A inviabilidade financeira é um entrave real para acolher, pois este movimento de manter uma ou mais crianças na família gera um custo extraordinário para os acolhedores. Argumentar que a profissionalização iria desvalorizar o atendimento estimulando o interesse somente financeiro não cabe aqui. Acolher por dinheiro não seria um bom negócio já que o trabalho de cuidar de crianças advindas de situações vulneráveis supera qualquer remuneração. O talento para o acolhimento certamente tem que existir, caso contrário, o trabalho não flui.

A política pública deve ser efetivada, entretanto da forma como foi desenhada não prevê profissionalização do acolhimento e direciona um valor insuficiente para dar conta das

\section{POLÊM!CA $\mid$ LABORE}

Polêmica - Revista Eletrônica da Uerj - Rua São Francisco Xavier, 524, $1^{\circ}$ andar bloco D, sl.1001 • Tels.: +55 21 2334-4088 / 4087 • http://www.e-publicacoes.uerj.br/index.php/polemica/index http://www.labore.uerj.br • laboreuerj@yahoo.com.br 
demandas das crianças. Em Portugal há um cenário similar no que se refere às necessidades financeiras. Delgado (2013, p. 140) pontua a fala dos acolhedores a esse respeito: “consideramos que seria importante um reforço dos apoios prestados às famílias de acolhimento, designadamente, ao nível econômico, com particular atenção às famílias com crianças que apresentam problemas de saúde”.

Destacamos aqui a necessidade de se repensar o formato atual de voluntariado para as famílias acolhedoras para além do sentimento de solidariedade: valorizar os protagonistas, reconhecê-los e empoderá-los, dando-lhes o devido valor material e emocional para que possam atingir o patamar da proteção integral por meio de ações cuidadoras e protetivas.

\section{Considerações finais}

A partir da reflexão sobre o acolhimento entende-se que seu percurso brasileiro tem formatos particulares. Da informalidade ao respaldo legal e comunitário, sua prática vem sendo redesenhada durante algumas décadas. Pensadores do desenvolvimento humano em diferentes áreas de pesquisa constataram a importância de se preservar os vínculos familiares e sociais. Atores do Sistema de Garantia de Direitos (SGD-CONANDA, 2006) hoje refletem a respeito da importância do trabalho social com famílias e de seu reconhecimento enquanto protagonistas na efetivação das políticas públicas.

O caráter voluntário do processo de acolhimento brasileiro e a inexistência de uma política de profissionalização tem sido reconhecido como um entrave na efetivação dessa modalidade protetiva, pois constata-se que as famílias dispostas a acolher necessitam de uma maior retaguarda financeira para que possam, cada vez mais, atender à crescente demanda de proteção de uma parcela da população carente de cuidados. Quanto maior o número de pais acolhedores, mais próxima parece estar a possibilidade de efetivação desta medida. É necessário problematizar as formas de proteção e incluir os serviços de famílias acolhedoras nas pautas de discussão dos legisladores, gestores e movimentos sociais.

A gestão adequada das famílias acolhedoras é foco de grande importância para o bom desenvolvimento dos serviços. Sem famílias adequadamente selecionadas, treinadas e acompanhadas, a medida protetiva corre riscos. É fundamental subsidiar a guarda dessas crianças de maneira a torná-la benéfica e eficaz. Hoje os processos seletivos das famílias dispostas a acolher variam de acordo com a localidade. Esse é um grande desafio já que os

\section{POLÊM!CA $\mid$ LABORE}


profissionais ligados a este tipo de serviço, em geral, não têm formação adequada para realizar o trabalho. Carecem, igualmente, de treinamento e supervisão continuada.

A tradição de uma cultura voltada para a institucionalização e a prática de não valorizar trabalhadores sociais tem facilitado uma abordagem particular no cuidado com a infância brasileira em vulnerabilidade. A mudança de olhar para estes cuidadores, valorizando-os, certamente facilitará intervenções políticas no sentido de gerar mudanças na prática de proteção. A abordagem atual de acolhimento parece incoerente com as necessidades das crianças. É necessário aprender com a transição de um modelo assistencialista para outro de proteção integral e comprometer-se politicamente com o investimento na garantia de direitos de maneira viável. A mudança de mentalidade deve acompanhar o que determina a lei: proteger e garantir a convivência familiar e comunitária.

É possível profissionalizar as famílias acolhedoras no Brasil? A quem interessa? Esse artigo não pode responder, mas procurou levantar novas direções de pesquisa, também no campo da Psicologia. Pretendeu mostrar a necessidade da implementação real, nos termos da previsão legal, de outras possibilidades de atendimento a casos que não raro envolvem violência e sofrimento psíquico em jovens vidas. São quadros que podem ser agravados, apesar das soluções serem alcançáveis.

\section{Referências}

ASSIS, S.G. e FARIAS, L.O.P. (Orgs.). Levantamento nacional das crianças e adolescentes em serviço de acolhimento. São Paulo: Hucitec, 2013.

AZEVEDO, R. C. O Conselho tutelar e seus operadores: O significado social e político da instituição - um olhar sobre os Conselhos Tutelares de Fortaleza/Ceará. (Dissertação não publicada) Fortaleza: Universidade Estadual do Ceará, 2007.

BAPTISTA, R. F. Acolhimento familiar, experiência brasileira: reflexões com foco no Rio de Janeiro (Dissertação de Mestrado). Pontifícia Universidade Católica do Rio de Janeiro (PUC-Rio), RJ, Brasil, 2006.

Infâncias partidas: reflexões sobre acolhimento familiar. Manuscrito não publicado. Universidade Estácio de Sá (UNESA). Rio de janeiro, 2014.

BRASIL. E. D. O conceito de acolhimento familiar na ótica de vários atores estratégicos. In: CABRAL, C. (Ed.). Colóquio Internacional sobre Acolhimento Familiar. Rio de Janeiro: Terra dos Homens, 2004.

BRASIL. Código de Menores. Decreto nº 17.943-A de 12 de outubro de 1927, revogado pela Lei $\mathrm{n}^{\circ} 6.697$ de 1979, 1927.

Lei 560/49. Criação do serviço de Colocação Familiar, junto aos Juízos de Menores. Assembleia Legislativa do Estado de São Paulo. Secretaria Geral Parlamentar. Departamento de documentação e informação. Disponível em: <http://www.al.sp.gov.br/norma/?id=40468>. Acesso em: 12 out. 2014.

\section{POLÊM!CA $\mid$ LABORE}

Polêmica - Revista Eletrônica da Uerj - Rua São Francisco Xavier, 524, $1^{\circ}$ andar bloco D, sl.1001 • Tels.: +55 21 2334-4088 / 4087 • http://www.e-publicacoes.uerj.br/index.php/polemica/index http://www.labore.uerj.br • laboreuerj@yahoo.com.br 
Lei no 8069 de 13 de Julho. Estatuto da Criança e do Adolescente. 1990. Disponível em: <http://www.planalto. gov.br/cci vil_03/leis/18069.htm>. Acesso em: 10 mar. 2014.

Lei no 8242 de 12 de outubro. Cria o Conselho Nacional dos Direitos da Criança e do Adolescente (CONANDA) e dá outras providências. Presidência da República, Casa Civil, Subchefia para Assuntos Jurídicos, 1991.

Lei $\mathbf{n}^{\mathbf{0}}$ 12.010, de 3 de agosto. Dispõe sobre adoção; altera as Leis $\mathrm{n}^{\text {os }}$ 8.069, de 13 de julho de 1990 Estatuto da Criança e do Adolescente, 8.560, de 29 de dezembro de 1992; revoga dispositivos da Lei ${ }^{0}{ }^{10.406}$, de 10 de janeiro de 2002 - Código Civil, e da Consolidação das Leis do Trabalho - CLT, aprovada pelo DecretoLei $n^{0} 5.452$, de $1^{\circ}$ de maio de 1943; e dá outras providências. Presidência da República, Casa Civil, Subchefia para Assuntos Jurídicos, 2009a.

. Presidência da República, Secretaria Especial dos Direitos Humanos, Ministério do Desenvolvimento Social e Combate à Fome. Orientações Técnicas: serviços de acolhimento para crianças e adolescentes. Brasília: CNAS, Conanda, 2009b.

Ministério do Desenvolvimento Social e Combate à Fome. Política Nacional de Assistência Social. Brasília, DF: Secretaria Nacional de Assistência Social, 2004.

Ministério do Desenvolvimento Social e Combate à Fome. Plano Nacional de Promoção, Proteção e Defesa do Direito de Crianças e Adolescentes à Convivência Familiar e Comunitária. Presidência da República. Brasília, DF: SEDH, MDS, CONANDA, 2006.

Ministério do Desenvolvimento Social e Combate à Fome, Secretaria Nacional de Assistência Social (SNAS). Resolução 109, de 11 de novembro de 2009 aprova a Tipificação Nacional de Serviços Socioassistenciais. 2013. Disponível em:

<http://www.mds.gov.br/webarquivos/publicacao/assistencia_social/Normativas/tipificacao.pdf>. Acesso em: 03 jul. 2015.

CANTALICE, L. B. O. A produção do conhecimento em torno dos Conselhos Tutelares: uma análise de teses e dissertações. In: SOUZA FILHO, R. et al. Conselhos Tutelares: desafios teóricos e práticos da garantia de direitos da criança e do adolescente. Juiz de Fora: UFJF, 2011. Disponível em:

<http://www.editoraufjf.com.br/files/Livro_CT_-_Impresso_DI_-_AC_Totinho.pdf>. Acesso em: 04 ago. 2015.

CONSELHO Municipal dos Direitos da Criança e do Adolescente. Política de Abrigo. CMDCA/RJ. Deliberação nº 032/96. Rio de Janeiro, 2003.

CONANDA. Conselho Nacional de Direitos da Criança e do Adolescente. Resolução no 113, de 19/ 04/ 2006. Brasília. Disponível em: <http://www.mprs.mp.br/infancia/legislacao/id2410.htm>. Acesso em: 20 mai. 2015.

COSTA, N. R. do A., \& ROSSETTI-FERREIRA, M. C. Acolhimento familiar: uma alternativa de proteção para crianças e adolescentes. Psicologia: Reflexão e Crítica, 22(1), 111-118, 2009. Disponível em: <http://www.scielo.br/scielo.php?script=sci_arttext\&pid=S010279722009000100015\&lng=en\&tlng=pt. 10.1590/S0102-79722009000100015>. Acesso em: 10 set. 2015.

DANTAS, E. \& LUNA, M. Diversity in the recognized forms of Foster Care: the Latin American View. Boletín Electrônico del Servicio Social Internacional. Agosto, 2009. Disponível em: <www.issssi.org/2009/index.php?id=79>. Acesso em: 08 set. 2014.

DELGADO, P. O Acolhimento Familiar em Portugal. Conceitos, práticas e desafios. Psicologia \& Sociedade; 22 (2): 336-344, 2010. Disponível em: <http://www.scielo.br/pdf/psoc/v22n2/14.pdf>. Acesso em: 15 out. 2015.

A reforma do acolhimento familiar de crianças: conteúdo, alcance e fins do novo regime jurídico. Análise Social, 45(196), 555-580, 2010.

\section{POLÊM!CA $\mid$ LABORE}

Polêmica - Revista Eletrônica da Uerj - Rua São Francisco Xavier, 524, $1^{\circ}$ andar bloco D, sl.1001 • Tels.: +55 21 2334-4088 / 4087 • http://www.e-publicacoes.uerj.br/index.php/polemica/index http://www.labore.uerj.br • laboreuerj@yahoo.com.br 
(coord.). Acolhimento familiar de crianças. Evidências do presente, desafios para o futuro. Porto, Portugal: Mais leituras, 2013.

DIAS, M.S. de L. \& Silva, R.S.B. O histórico de institucionalização de crianças e adolescentes. Tuiuti: Ciência e Cultura, n. 45, 177-188, 2012.

FONSECA, C. Da circulação de crianças à adoção internacional: questões de pertencimento e posse. Dossiê repensando a infância. Cadernos Pagu (26)11-43, 2006. Disponível em:

<http://www.scielo.br/scielo.php?script=sci_arttext\&pid=S010483332006000100002\&lng=en\&tlng=pt. 10.1590/S0104-83332006000100002>. Acesso em: 20 nov. 2014.

GEORGE, S., \& VAN OUDENHOVEN, N. Apostando al acogimiento familiar - un estudio comparativo internacional (M. Soledad Franco, Trans.). Amberes, Bélgica: International Foster Care Organisation, 2003.

GIRARD, T. Uma família comprometida. In: CABRAL, C. (Ed.). Colóquio Internacional sobre Acolhimento Familiar. Rio de Janeiro: Terra dos Homens, 2004.

GUERRA, V. N. A. Violência de pais contra filhos: a tragédia revisitada. 7. ed. São Paulo: Cortez, 2011.

JOYCE, R. \& SIBIETA, L. An assessment of Labour's record on income inequality and poverty. Oxf. Rev. Econ. Policy 29(1), 178-202, 2013. Disponível em: <http://oxrep.oxfordjournals.org/content/29/1/178.full>. Acesso em: 11 dez. 2013.

LÓPEZ, M. L.; DEL VALLE, J. F. \& ARTEAGA, A.B. Estrategias para la captación de familias acogedoras. Papeles del Psicólogo. Vol. 31(3), pp. 289-295, 2010.

LUNA, M. (Coord.). Informe Latinoamericano. Situación de la niñez sin cuidado parental oen riesgo de perderlo en América latina. Contextos, causas y respuestas. Ciudad Autónoma de Buenos Aires, Argentina, 2010.

MARCÍLIO, M. L. (Org.). Família, mulher, sexualidade e igreja na história do Brasil. São Paulo: Ed. Loyola, 1993.

MIRANDA, P. \& ZAMORA, M. H. Direitos fundamentais de crianças e adolescentes em favelas cariocas: problematizando a produção de negligência. Polêmica, 8(1), 34-38, 2009.

ONU. Organização das Nações Unidas. Convenção Internacional sobre os Direitos da Criança. New York, USA: Assembleia Geral das Nações Unidas, 1989.

PIOVESAN, F. FACHIN, M. G. (Org.). Direitos Humanos na ordem contemporânea: proteção nacional, regional e global. 1. ed. Curitiba: Juruá. v. 6. 492p, 2015.

RIZZINI, I. Assistência à infância no Brasil. Uma análise de sua construção. Rio de Janeiro: Editora Universitária Santa Úrsula, 1993.

O Século perdido: raízes históricas das políticas públicas para infância no Brasil. Rio de Janeiro: Petrobras, BR/ Ministério da Cultura: Editora Universitária Santa Úrsula, 1997.

VALENTE, J. Acolhimento familiar: validando e atribuindo sentido às leis protetivas. Serv. Soc.Soc. (111), 576-598, 2012. Disponível em:

<http://www.scielo.br/scielo.php?script=sci_arttext\&pid=S010166282012000300010\&lng=en\&tlng=pt. 10.1590/S0101-66282012000300010>. Acesso em: 12 jan. 2015.

Família acolhedora: as relações de cuidado e de proteção no serviço de acolhimento. São Paulo: Paulus, 2013.

VENÂNCIO, R. P. Famílias abandonadas: assistência à criança de camadas populares no Rio de Janeiro e em Salvador - Séculos XVIII e XIX. Campinas, SP: Papirus, 1999.

\section{POLÊM!CA $\mid$ LABORE}

Polêmica - Revista Eletrônica da Uerj - Rua São Francisco Xavier, 524, $1^{\circ}$ andar bloco D, sl.1001 • Tels.: +55 21 2334-4088 / 4087 • http://www.e-publicacoes.uerj.br/index.php/polemica/index http://www.labore.uerj.br • laboreuerj@yahoo.com.br 
VILHENA, J. DE, SOUZA, A. C. B. DE, UZIEL, A. P., ZAMORA, M. H. \& NOVAES, J. V. Que família? Provocações a partir da homoparentalidade. Revista Mal-estar e subjetividade, 11 (4), 1639-1658, 2011.

Recebido em: 14/02/2015.

Aceito em: 21/03/2016.

\section{POLÊM!CA $\mid$ LABORE}

